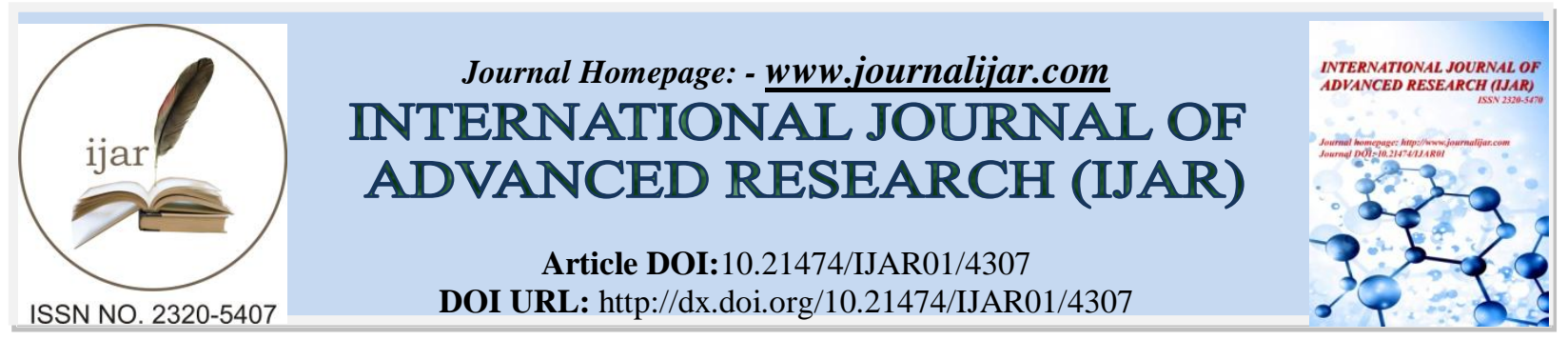

RESEARCH ARTICLE

\title{
GROWTH, STRUCTURAL, MORPHOLOGICAL AND OPTICAL CHARACTERIZATIONS OF PURE AND CADMIUM DOPED CALCIUM OXALATE MONOHYDRATE CRYSTALS
}

R. Selvaraju and S. Sulochana

Engineering Physics, FEAT, Annamalai University, Annamalai Nagar.

\section{Manuscript Info}

Manuscript History

Received: 20 March 2017

Final Accepted: 25 April 2017

Published: May 2017

Key words:-

Caox, FTIR, XRD, SEM-EDX, and UV-

Visible.

\section{Abstract}

The human urinary calculi are mainly formed from Calcium Oxalate Monohydrate (COM), Magnesium Ammonium Phosphate Hexahydrate (MAPH) and Uric acid crystals. It is mainly classified into two types of hydrates, Calcium Oxalate Monohydrate (whewellite) and Calcium Oxalate Dehydrate (weddelite). The pure calcium oxalate monohydrate and cadmium doped Calcium Oxalate Monohydrate (CdCaoxM) crystals are grown by single diffusion gel growth method. The grown crystals are characterized by FTIR, FTRaman, XRD, SEM-EDX and UV-Visible analysis.

Copy Right, IJAR, 2017,. All rights reserved.

\section{Introduction:-}

The formation of urinary calculi is known as nephrolithiasis. Urinary calculi affected too many people in various age groups. In this world, urinary calculi are one of the most hazardous and painful existing urological disorder causing threats to the global population. $(1,2)$. Calcium containing stones are the most common comprising about $75 \%$ of all urinary calculi which may be in the form of pure calcium oxalate $(50 \%)$ or calcium phosphate $(5 \%)$ and a mixture of both $(45 \%)$. Calcium oxalate stones are found in two different varieties, Calcium Oxalate Monohydrate (COM) or whewellite and Calcium Oxalate Dehydrate (COD) or weddelitte. Many factors affect the growth of urinary calculi. Investigation of the urinary stones showed large number of trace elements including $\mathrm{Cd}, \mathrm{Pb}, \mathrm{Zn}$, $\mathrm{Mg}, \mathrm{Sr}, \mathrm{Cr}, \mathrm{Mn}, \mathrm{Ni}, \mathrm{Cu}, \mathrm{Co}, \mathrm{Au}, \mathrm{Ti}, \mathrm{Bi}$, etc., along with the main constituents (3). Urinary calcium excretion is influenced by dietary intake of calcium, sodium, protein, carbohydrates, alcohol and potassium (4). The case of insufficient intake of water or due to the decreased rate of excretion, the crystallogenic substances in the urine can be concentrated, leading to crystal formation. A change in the $\mathrm{pH}$ value in the urine can lead to the crystal growth $(5,6)$. Humans are exposed to cadmium is if no use to the human body and is toxic even at low levels. The negative effects of cadmium is of no use to the human body and numerous and can impact nearly all systems in the body, including cardiovascular reproductive, the kidneys, eyes and even the brain. The size and morphology of the stones were examined using optical microscopy, while their component and crystalline phases were determined by Fourier Transform Infrared spectroscopy, Ultraviolet spectroscopy and X-ray powder diffraction (7). The scanning electron microscopic studies help in understanding the surface morphology and ultra structure of the calculi (8). Invitro growth of calcium oxalate monohydrate crystal by single diffusion gel growth method in silica gel medium. The harvested crystals are characterized by Fourier Transform Infrared spectroscopy, X-ray diffraction, thermal analysis and the effect of aqueous extracts of Tribulus terrestris are studied on the inhibition growth of crystals in vitro and may be useful in prevention and cure of this crystal induce ailments(9). In the present paper is to report the growth of pure calcium oxalate monohydrate and cadmium doped calcium oxalate monohydrate crystals in silica gel method. The harvested crystals are characterized by FTIR, FT-Raman, XRD, SEM-EDX and UV-visible analysis. 


\section{Materials and Methods:-}

\section{Crystal Growth:-}

The growth of pure calcium oxalate monohydrate and cadmium doped calcium oxalate monohydrate crystal was carried out in silica gel. All the chemicals used in this experiment are of AR grade. The borosilicate glass test tubes of $2.5 \mathrm{~cm}$ diameter and $20 \mathrm{~cm}$ length were used as crystallizing vessels. In a single diffusion gel method, gel was set by mixing sodium meta silicate solution of density $1.03 \mathrm{~g} / \mathrm{cm}^{-3}$ was adjusted to a $\mathrm{pH}$ of 6 by adding $5 \%$ glacial acetic acid (10). Calcium chloride and cadmium chloride one of the reactants was incorporated inside the gel. After the gel was set an aqueous solution of oxalic acid was slowly added over the gel and the experiments were conducted at room temperature. Within a day, a white column of tiny crystals were formed. The growth was completed within a period of 21 days were grown which are as shown in Fig 1(a) and 1(b). The growth and harvested cadmium doped calcium oxalate monohydrate crystals are as shown in Fig. 2(a) and 2(b).

Different parameters such as concentration of reactants, $\mathrm{pH}$ of gel, impurities in the solvent, gel setting time, etc, have considerable effect on growth rates.

Table 1:- The optimum condition for the growth of pure and cadmium doped calcium oxalate monohydrate crystal.

\begin{tabular}{|c|c|c|}
\hline S. No & Parameter & Optimum condition \\
\hline 1 & Density of sodium meta silicate & $1.03 \mathrm{gm} / \mathrm{cm}^{-3}$ \\
\hline 2 & $\mathrm{pH}$ of gel & 6 \\
\hline 3 & Concentration of $\mathrm{CaCl}_{2}$ & $1 \mathrm{M}$ \\
\hline 4 & Concentration of $\mathrm{CdCl}_{2}$ & $0.01 \mathrm{M}$ \\
\hline 5 & Concentration of $\mathrm{C}_{2} \mathrm{H}_{2} \mathrm{O}_{4}$ & $1 \mathrm{M}$ \\
\hline 6 & Gel setting period & 2 days \\
\hline 7 & Gel aging & 1 month \\
\hline 8 & Period of growth & 21 days \\
\hline 9 & Temperature & Room temperature \\
\hline
\end{tabular}

Fig. 1. (a). Growth of pure CaOxM crystal

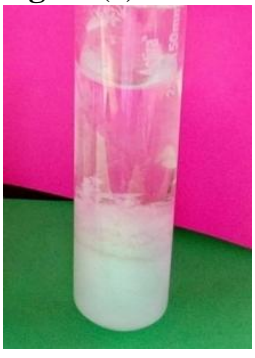

Fig.2. (a) Growth of CdCaoxM crystal

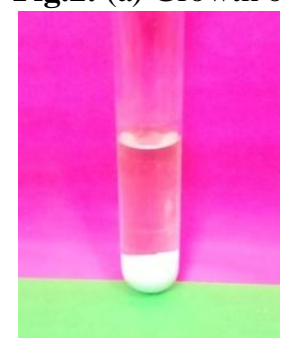

Fig. 1.(b). The harevested pure $\mathrm{CaOxM}$ crystal

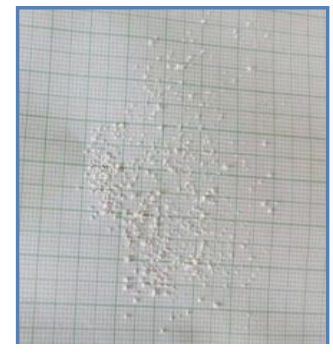

Fig. 2:-(b) The harvested CdCaoxM crystal .

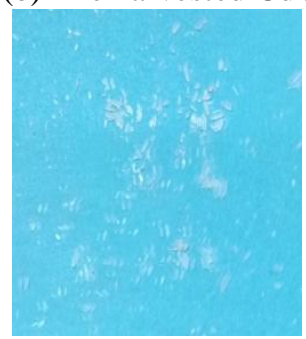

\section{Characterization Techniques:-}

FTIR spectrum is recorded by $\mathrm{KBr}$ pellet technique using Perkin Elmer FTIR spectrometer with the range 400$4000 \mathrm{~cm}^{-1}$ is available at Centralised Instrumentation Science Laboratory, Department of Physics, St. Joseph College, Tiruchirappalli. FT-Raman spectra were recorded in the range of $4000 \mathrm{~cm}^{-1}$ to $100 \mathrm{~cm}^{-1}$ using BRUCKER, Model RFS27. FT-Raman spectrum which are available at Sophisticated Analytical Instrument Facility (SAIF). Indian Institute of Technology (IIT), Chennai, Tamilnadu, South India. Powder X-ray diffraction of the samples are carried out by EXPERT-PRO with $\mathrm{CuK} \alpha$ radiation $\left(\lambda=1.5418 \mathrm{~A}^{\circ}\right)$ is available at Department of Physics, Alagappa 
University, Karaikkudi. The morphology of pure calcium oxalate monohydrate and cadmium doped calcium oxalate monohydrate crystal was studied by JEOL, JSM 6390 SEM and the presence of elemental composition was calculated by OXFORD instruments, TINCA pental FETX3 EDX method is available at Karunya University, Coimbatore. Absorption spectra of pure calcium oxalate monohydrate and cadmium doped calcium oxalate monohydrate crystals were recorded using a UV-2400 PC Series UV-Visible spectrophotometer over the wavelength range $200 \mathrm{~nm}$ to $900 \mathrm{~nm}$ at Science Instrumentation Centre, Department of Physics, Standard Fire Rajarathnam Women's College, Sivakasi.

\section{Results and Discussion:-}

The pure calcium oxalate monohydrate and cadmium doped calcium oxalate monohydrate crystals were grown by single diffusion gel growth technique and the harvested crystals are analyzed by FTIR, FT-Raman, XRD, SEMEDX and UV-Visible analysis are studied.

\section{Fourier Transform Infrared Spectroscopy:-}

The FTIR spectra of pure calcium oxalate monohydrate and cadmium doped calcium oxalate monohydrate crystals were as shown in Fig 3(a) and 3(b). The vibrational modes of pure calcium oxalate monohydrate and cadmium doped calcium oxalate monohydrate are presented in Table 2. In FTIR spectra, a strong band at $3431 \mathrm{~cm}^{-1}, 3433 \mathrm{~cm}^{-1}$ and $3061 \mathrm{~cm}^{-1}$, $3063 \mathrm{~cm}^{-1}$ is due to asymmetric and symmetric OH stretching while an intense absorptions band at $3261 \mathrm{~cm}^{-1}, 3259 \mathrm{~cm}^{-1}$ show intermolecular hydrogen bonded $\mathrm{OH}$ stretch. Intense absorption band at $1621 \mathrm{~cm}^{-1}, 1616 \mathrm{~cm}^{-1}$ and $1318 \mathrm{~cm}^{-1}$, $1319 \mathrm{~cm}^{-1}$ can be assigned to asymmetric and symmetric $\mathrm{C}=\mathrm{O}$ stretching bands specific to the calcium oxalate monohydrate. The sharp band at $886 \mathrm{~cm}^{-1}, 885 \mathrm{~cm}^{-1}$ is due to C-C stretching vibrations which confirm the existence of oxalate group in calcium oxalate monohydrate. The sharp peaks at $781 \mathrm{~cm}^{-1}, 781 \mathrm{~cm}^{-1}$ is due to O-C $=\mathrm{O}$ and the wideband at $665 \mathrm{~cm}^{-1}, 662 \mathrm{~cm}^{-1}$ can be assigned to the bending modes of the water molecule. However, the peak at $518 \mathrm{~cm}^{-1}$ and $516 \mathrm{~cm}^{-1}$ is assigned to the presence of metal-oxygen bond (10). Thus FTIR reveals that the growth of calcium oxalate monohydrate crystals was due to the presence of $\mathrm{O}-\mathrm{H}$ stretching, $\mathrm{C}=\mathrm{O}, \mathrm{C}-\mathrm{C}, \mathrm{O}-\mathrm{C}=\mathrm{O}$ and $\mathrm{M}=\mathrm{O}$ bonds.

Fig 3:- (a). FT-IR spectrum of pure calcium oxalate monohydrate crystal.

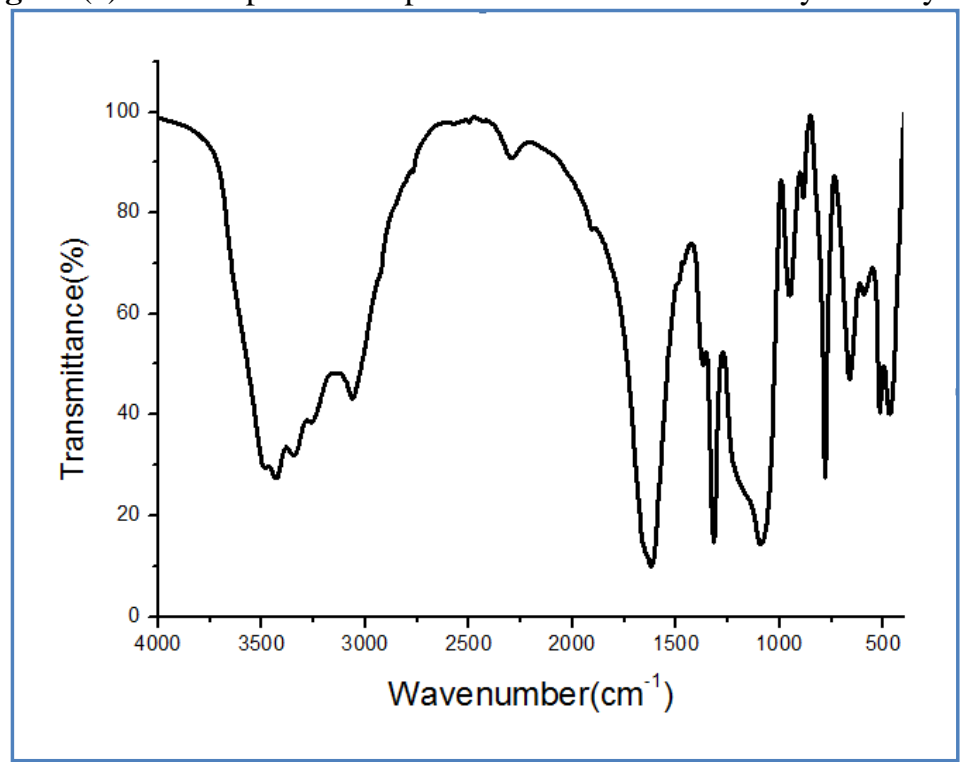


Fig. 3:- (b). FT-IR spectrum of cadmium doped calcium oxalate monohydrate crystal.

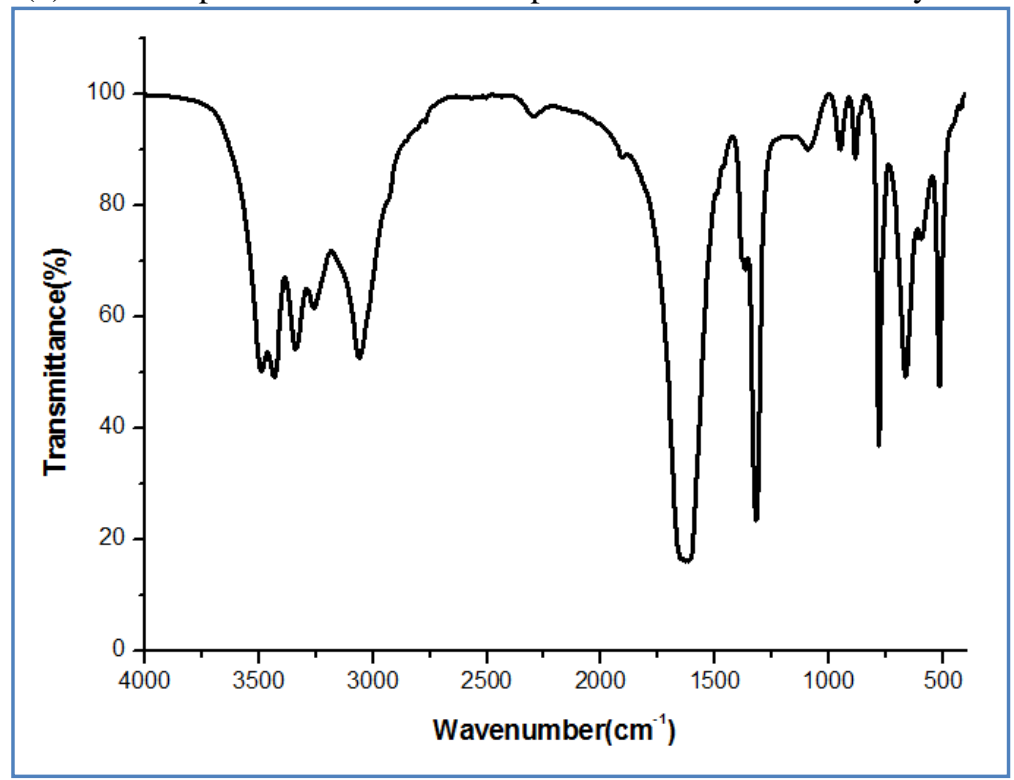

Table 2:- FTIR wave numbers and tentative assignment of pure calcium oxalate monohydrate and cadmium doped calcium oxalate monohydrate crystal.

\begin{tabular}{|c|c|c|}
\hline $\begin{array}{c}\text { Pure calcium oxalate } \\
\text { monohydrate } \\
\text { wavenumber } \mathrm{cm}^{-1}\end{array}$ & $\begin{array}{c}\text { Cadmium doped calcium } \\
\text { oxalate monohydrate } \\
\text { wavenumber } \mathrm{cm}^{-1}\end{array}$ & Tentative band Assignment \\
\hline 3431 & 3433 & Asymmetric OH stretch \\
\hline 3063 & 3061 & Symmetric OH stretch \\
\hline 3262 & 3259 & Inter molecule $\mathrm{H}_{2}$ bonded OH stretch \\
\hline 1621 & 1616 & Asymmetric C=O stretch \\
\hline 1318 & 1319 & Symmetric C=O stretch \\
\hline 1092 & 1092 & Asymmetric C-O stretch \\
\hline 951 & 950 & Symmetric C-O stretch \\
\hline 886 & 885 & C-C stretch \\
\hline 781 & 781 & O-C=O stretch \\
\hline 662 & 665 & OH wagging \\
\hline 516 & 518 & M-O bond \\
\hline
\end{tabular}

These peaks are found to be present in the spectrum of cadmium doped calcium oxalate monohydrate crystals confirms the presence of the element cadmium.

\section{Fourier Transform Raman studies:-}

FT-Raman spectra of the pure calcium oxalate and cadmium doped calcium oxalate monohydrate crystals as shown in Fig 4(a) and 4(b) and Table 3 shows the vibration assignment of pure calcium oxalate monohydrate and cadmium doped calcium oxalate monohydrate crystals.

Table 3:-Vibration band assignment of pure calcium oxalate monohydrate and cadmium doped calcium oxalate monohydrate crystal.

\begin{tabular}{|c|c|c|}
\hline $\begin{array}{l}\text { Pure calcium oxalate } \\
\text { monohydrate } \\
\text { number in } \mathrm{cm}^{-1}\end{array}$ & $\begin{array}{l}\text { Cadmium doped calcium oxalate } \\
\text { monohydrate wave number in } \mathrm{cm}^{-1}\end{array}$ & Vibration band assignment \\
\hline 3088 & 3058 & $\mathrm{OH}$ stretching \\
\hline 3048 & - & $\mathrm{OH}$ stretching \\
\hline 2828 & - & $\mathrm{CH}_{3}$ stretching \\
\hline
\end{tabular}




\begin{tabular}{|c|c|c|}
\hline 2721 & - & C-H stretching \\
\hline 2223 & - & C-H stretching vibration \\
\hline 2181 & - & Stretching vibration of C-C \\
\hline 1895 & 1813 & Stretching vibration of C-C \\
\hline 1722 & 1727 & Stretching vibration of C-O \\
\hline 1628 & 1629 & C-O asymmetric stretching \\
\hline 1487 & 1488 & Vibration of C-O \\
\hline 1461 & 1462 & Vibration of C-O \\
\hline- & 1395 & O-C-O stretching mode \\
\hline 938 & 918 & PO ${ }_{4}^{3}$ bending \\
\hline 894 & 892 & C-C Stretching \\
\hline 595 & 592 & Phosphate bands \\
\hline 502 & 501 & O-C-O in plane bending \\
\hline
\end{tabular}

The spectra of pure calcium oxalate monohydrate and cadmium doped calcium oxalate monohydrate crystal shows $\mathrm{O}-\mathrm{H}$ stretching vibration between $3088 \mathrm{~cm}^{-1}$ and $3058 \mathrm{~cm}^{-1}, 3048 \mathrm{~cm}^{-1}$. The sharp bands at $1461 \mathrm{~cm}^{-1}, 1462 \mathrm{~cm}^{-1}$ and $1487 \mathrm{~cm}^{-1}, 1488 \mathrm{~cm}^{-1}$ are due to the $\mathrm{C}=\mathrm{O}$ vibration and $\mathrm{C}-\mathrm{O}$ symmetric stretching of pure calcium oxalate monohydrate and cadmium doped calcium oxalate monohydrate crystals. The less intense $1628 \mathrm{~cm}^{-1}$ and $1629 \mathrm{~cm}^{-1}$ band due to the $\mathrm{C}-\mathrm{O}$ asymmetric stretching and the $892 \mathrm{~cm}^{-1}, 894 \mathrm{~cm}^{-1}$ band due to the O-C-O plane bending of pure calcium oxalate monohydrate and cadmium doped calcium oxalate monohydrate(11).

Fig. 4:- (a). FT-Raman spectrum of pure calcium oxalate monohydrate crystal.

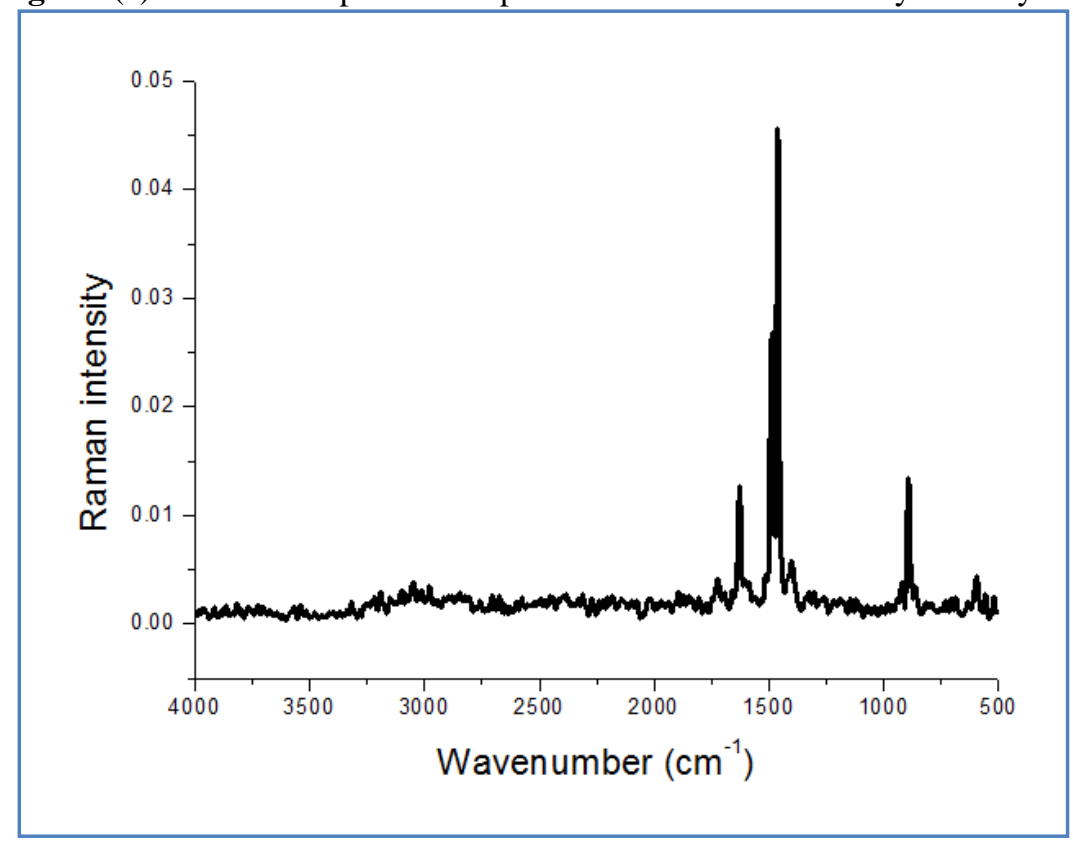


Fig. 4:- (b). FT-Raman spectrum of calcium oxalate monohydrate crystal.

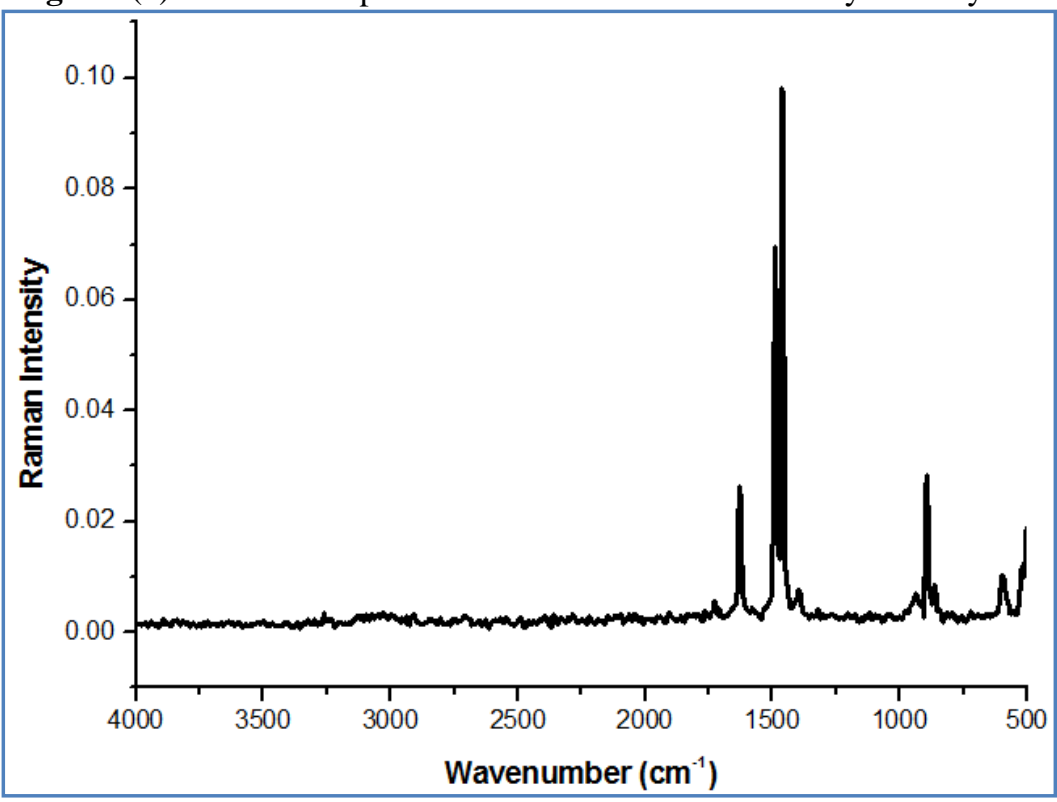

X-ray diffraction Analysis:-

The powder XRD pattern was recorded using diffractometer system=XPERT-PRO X-ray diffractometer with $\mathrm{CuK} \alpha$ radiation $\left(\lambda=11.546 \mathrm{~A}^{0}\right)$. The powder sample was scanned over the range $10^{0}$ to $60^{0}$ in at a rate of $1^{0}$ per minute. Fig 5(a) and 5(b) shows that the pure calcium oxalate and cadmium doped calcium oxalate monohydrate crystals.

The powder XRD analysis of the grown calcium oxalate monohydrate crystals was matched with the reported database using computer with PAN analytical software and result was matched with JCPDS File (14-0789) (12). The indexed powder data for the pure calcium oxalate and cadmium doped calcium oxalate monohydrate crystals are presented in Table.4 and 5. From the XRD data, it is observed that from the cell parameters of both pure calcium oxalate monohydrate and cadmium doped calcium oxalate monohydrate crystals belong to monoclinic system.

Fig. 5:- (a) X-ray diffraction analysis of pure calcium oxalate monohydrate crystal.

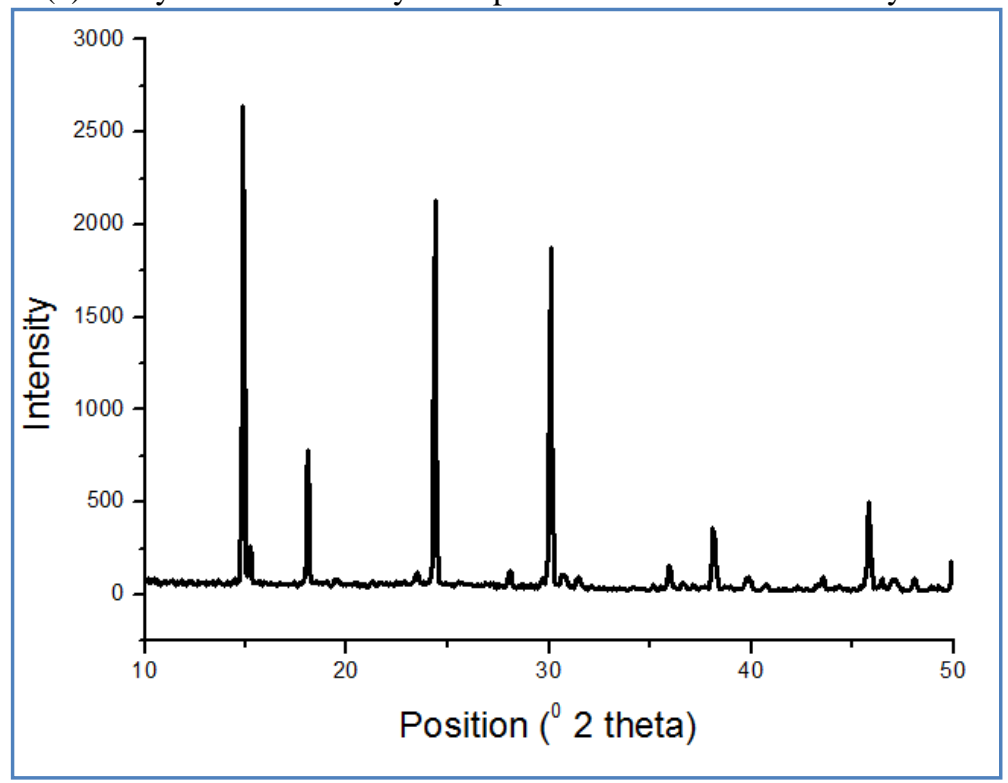


Fig 5:- (b). X-ray diffraction analysis of cadmium doped calcium oxalate monohydrate crystal.

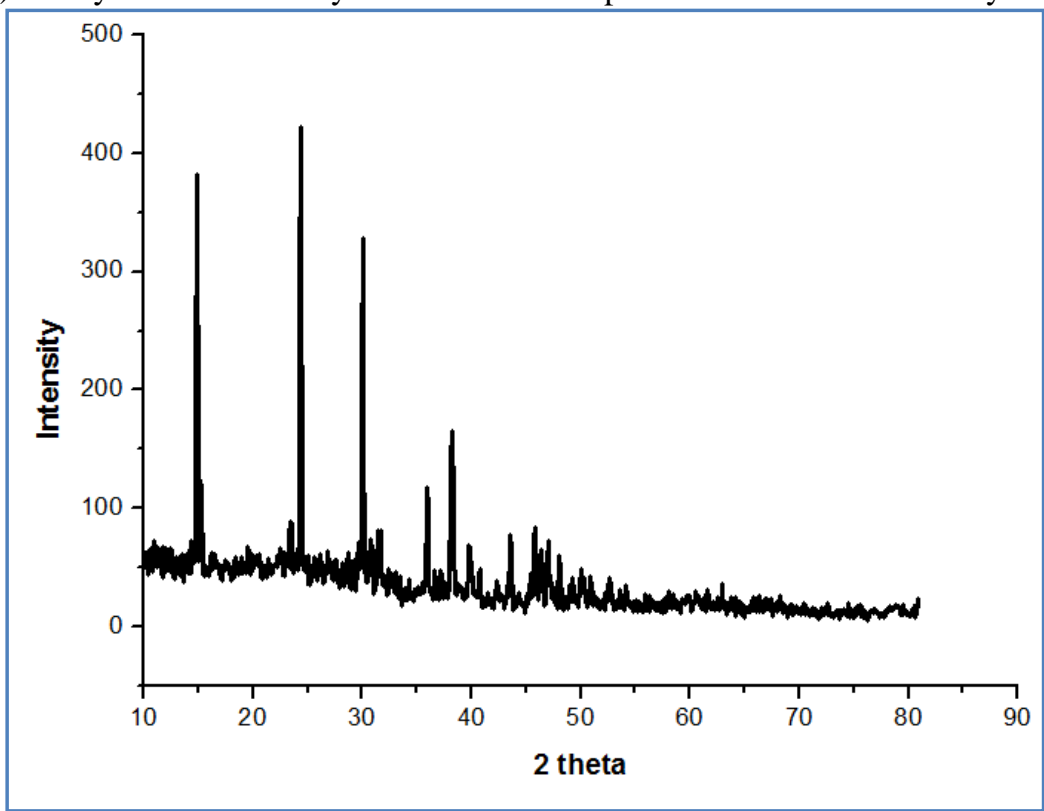

Table 4:- X-ray diffraction analysis of pure calcium oxalate monohydrate crystal.

\begin{tabular}{|c|c|c|c|c|c|c|}
\hline \multicolumn{3}{|c|}{ Standard value } & \multicolumn{3}{c|}{ Observed value } & \multirow{2}{*}{ hkl value } \\
\cline { 1 - 5 } $2 \theta$ & $\mathrm{I} / \mathrm{I}_{0}$ & $\mathbf{d}$-space & $2 \theta$ & $\mathrm{I} / \mathrm{I}_{0}$ & d-space & \\
\hline 14.927 & 100 & 5.93 & 14.875 & 100 & 5.95 & -101 \\
\hline 15.290 & 60 & 5.79 & 15.233 & 9 & 5.81 & 011 \\
\hline 19.579 & 40 & 4.53 & 19.588 & 2 & 4.53 & 101 \\
\hline 23.515 & 40 & 3.78 & 23.480 & 3 & 3.78 & -112 \\
\hline 24.365 & 98 & 3.65 & 24.364 & 81 & 3.65 & 020 \\
\hline 30.083 & 80 & 2.96 & 30.073 & 70 & 2.97 & -202 \\
\hline 31.439 & 40 & 2.84 & 31.419 & 2 & 2.83 & 121 \\
\hline 35.964 & 60 & 2.49 & 35.954 & 5 & 2.49 & 211 \\
\hline 36.663 & 20 & 2.44 & 36.629 & 2 & 2.45 & -213 \\
\hline 38.148 & 60 & 2.35 & 38.156 & 2 & 2.35 & 031 \\
\hline 40.795 & 40 & 2.26 & 40.749 & 1 & 2.21 & -204 \\
\hline 43.558. & 60 & 2.07 & 43.563 & 3 & 2.07 & 123 \\
\hline 45.835 & 60 & 1.97 & 45.836 & 17 & 1.97 & -303 \\
\hline 46.308 & 10 & 1.95 & 46.446 & 2 & 1.95 & 132 \\
\hline 47.199 & 10 & 1.92 & 47.096 & 2 & 1.92 & 222 \\
\hline 48.086 & 40 & 1.89 & 48.081 & 2 & 1.89 & 230 \\
\hline
\end{tabular}

Table 5:-X-ray diffraction analysis of cadmium doped calcium oxalate monohydrate crystal.

\begin{tabular}{|c|c|c|c|c|c|c|}
\hline \multicolumn{3}{|c|}{ Standard value } & \multicolumn{3}{c|}{ Observed value } & \multirow{2}{*}{ hkl value } \\
\cline { 1 - 5 } $\mathbf{2} \theta$ & ${\mathbf{I} / \mathbf{I}_{\mathbf{0}}}^{\mathbf{2}}$ & $\mathbf{d}-$-space & $\mathbf{2} \theta$ & $\mathbf{I}_{\mathbf{0}}$ & $\mathbf{d}-$ space & \\
\hline 14.927 & 100 & 5.93 & 14.895 & 95 & 5.94 & -101 \\
\hline 15.290 & 60 & 6.79 & 15.257 & 25 & 5.80 & 011 \\
\hline 18.585 & 20 & 3.77 & 23.475 & 16 & 3.78 & -112 \\
\hline 24.365 & 100 & 3.65 & 24.377 & 100 & 3.65 & 020 \\
\hline 30.083 & 80 & 2.97 & 30.086 & 75 & 2.97 & -202 \\
\hline 30.611 & 40 & 2.90 & 30.768 & 12 & 2.90 & 013 \\
\hline 31.449 & 40 & 2.93 & 31.550 & 12 & 2.83 & 121 \\
\hline 35.964 & 60 & 2.49 & 35.970 & 24 & 2.49 & 211 \\
\hline 36.663 & 20 & 2.41 & 36.648 & 7 & 2.42 & -123 \\
\hline
\end{tabular}




\begin{tabular}{|c|c|c|c|c|c|c|}
\hline 38.158 & 60 & 2.38 & 38.197 & 35 & 2.35 & 113 \\
\hline 39.780 & 40 & 2.26 & 39.768 & 12 & 2.26 & 014 \\
\hline 40.795 & 40 & 2.21 & 40.769 & 7 & 2.21 & -204 \\
\hline 42.379 & 20 & 2.13 & 42.413 & 3 & 2.13 & -132 \\
\hline 43.558 & 60 & 2.07 & 43.596 & 14 & 2.09 & -301 \\
\hline 45.835 & 60 & 1.99 & 45.830 & 15 & 1.97 & 024 \\
\hline 46.306 & 10 & 1.97 & 46.439 & 7 & 1.95 & -303 \\
\hline 46.966 & 40 & 1.93 & 46.958 & 9 & 1.93 & 310 \\
\hline 48.074 & 40 & 1.89 & 48.033 & 5 & 1.89 & 230 \\
\hline
\end{tabular}

The peaks in the XRD patterns which were obtained slightly shifted due to the addition of dopants which indicates that the dopants have entered into the lattice of the crystal. It is seen that the x-ray pattern is almost similar indicating the presence of cadmium has not affected the crystalline nature of the sample.

\section{Scanning Electron Microscopy -EDX Analysis:-}

The morphology of the pure calcium oxalate monohydrate and cadmium doped calcium oxalate monohydrate crystals were studied by SEM. Fig .6(a) and 6(b)shows the scanning electron microscope images of pure and cadmium doped calcium oxalate monohydrate crystals. The grown crystals are obtained in different morphologies such as monoclinic, prismatic, and hexagonal prismatic and plate like shape (13).

Fig. 6:- (a) SEM images of pure calcium oxalate monohydrate crystal.

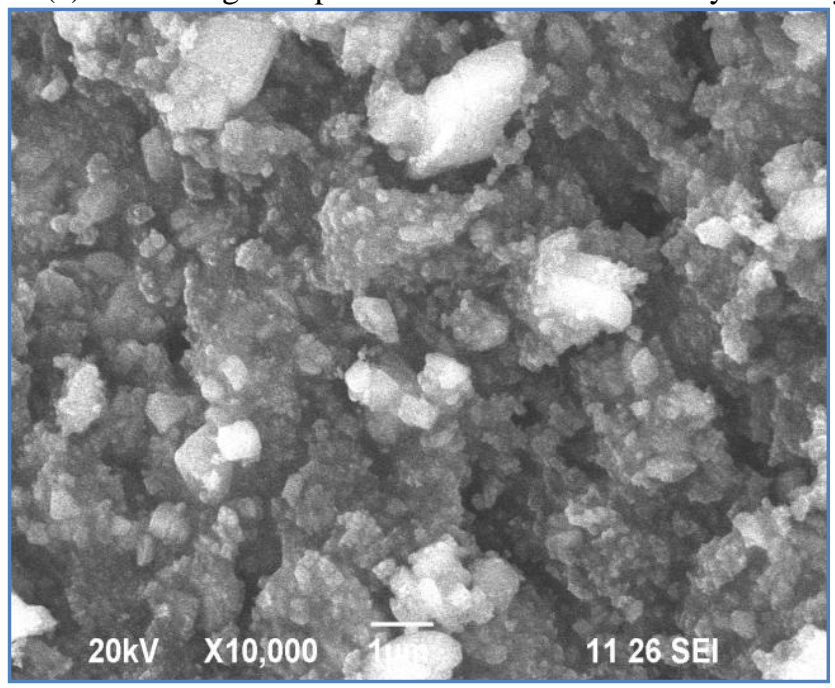

Fig.6:- (b). SEM images of cadmium doped calcium oxalate monohydrate crystal.

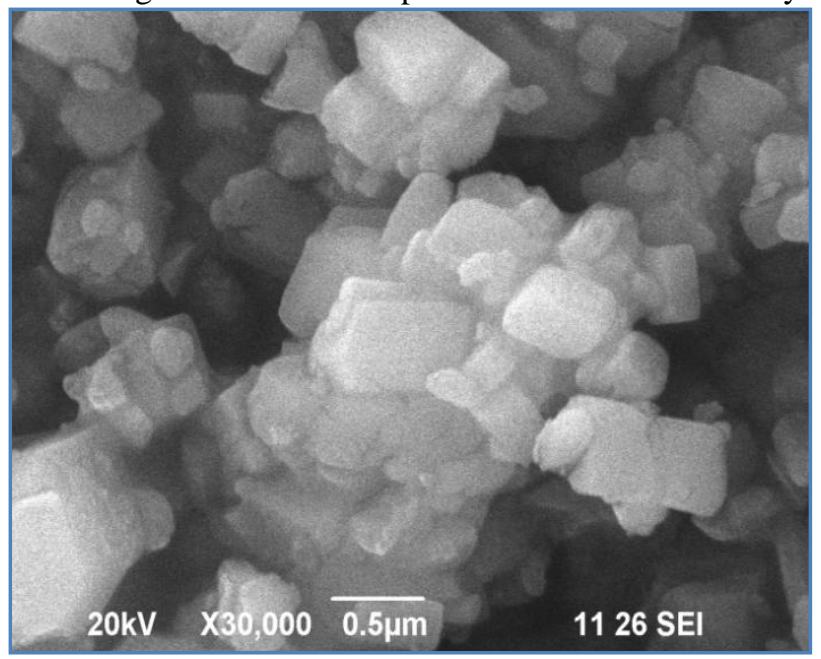


It was found that the structure of the grown crystals does not affect the morphology of the crystals by doping.

The presences of pure calcium and cadmium quantitative elemental analysis were performed on the application of energy dispersive X-ray analysis. The energy dispersive $\mathrm{x}$-ray analysis of pure calcium oxalate monohydrate and cadmium doped calcium oxalate monohydrate crystal as shown in Fig.7 (a) and 7(b).

Fig. 7:-(a). EDX spectrum of pure calcium oxalate monohydrate crystal.

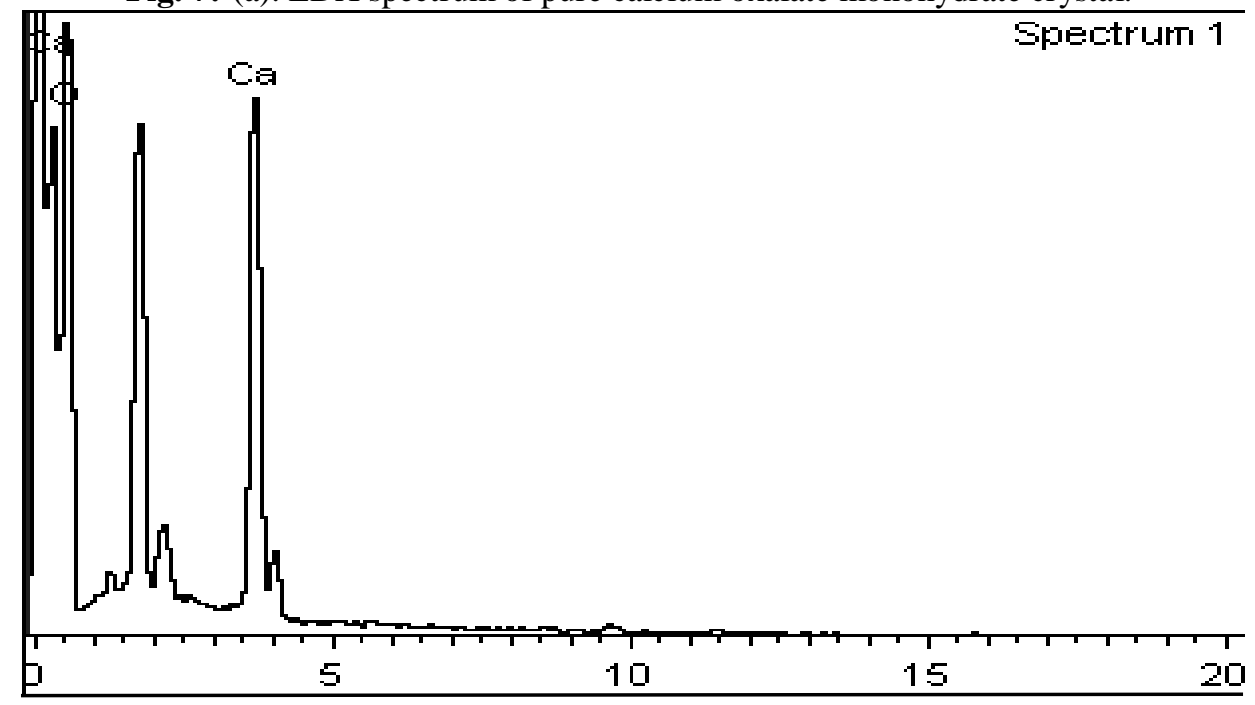

Table 6:- (a) EDX analysis of pure calcium oxalate monohydrate crystal.

\begin{tabular}{|c|c|c|}
\hline Element & Atomic weight\% & Mass weight\% \\
\hline $\mathrm{C}$ & 91.37 & 80.86 \\
\hline $\mathrm{Ca}$ & 8.63 & 19.14 \\
\hline Total & 100 & 100 \\
\hline
\end{tabular}

The atomic percentage of present element oxygen, calcium was found to be $91.37 \% 8.63 \%$ are present (14).

Fig. 7:- (b) EDX analysis of cadmium doped calcium oxalate monohydrate crystal.

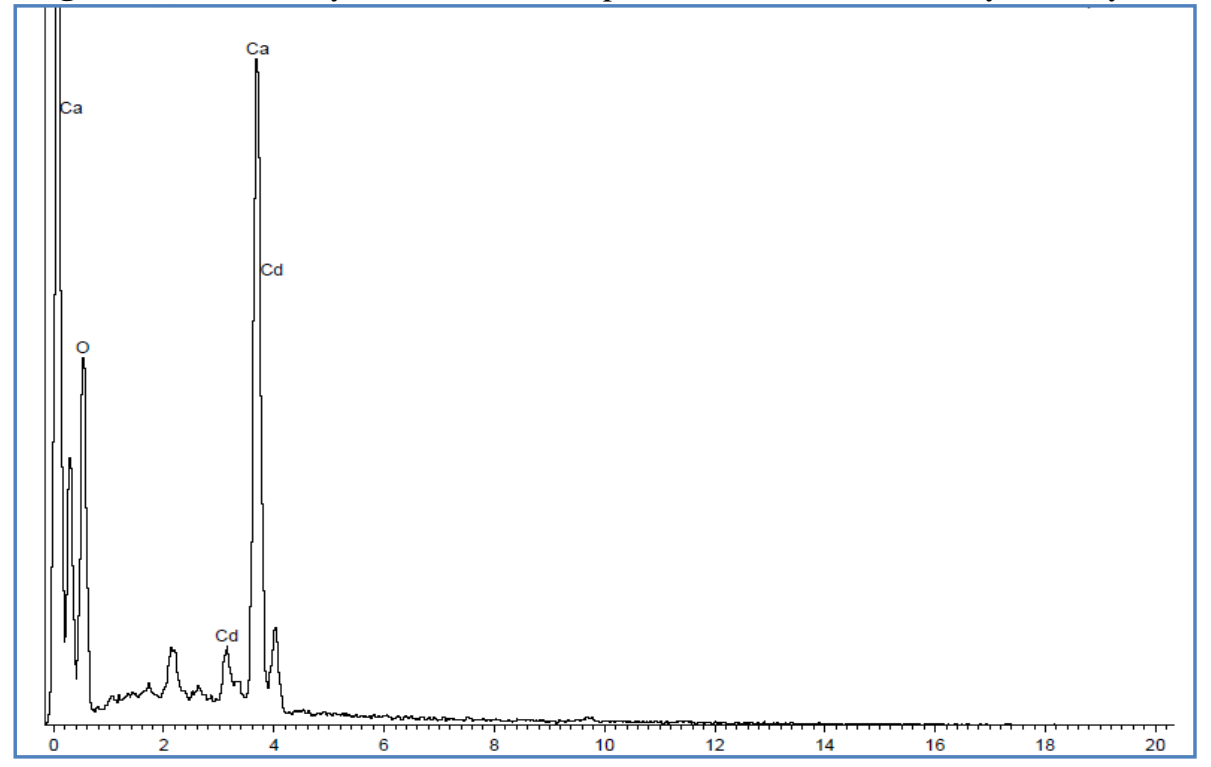


Table 6:- (b). EDX analysis of cadmium doped calcium oxalate monohydrate crystal.

\begin{tabular}{|c|c|c|}
\hline Element & Atomic weight\% & Mass weight\% \\
\hline $\mathrm{O}$ & 86.50 & 65.92 \\
\hline $\mathrm{Ca}$ & 12.59 & 25.34 \\
\hline $\mathrm{Cd}$ & 0.91 & 5.14 \\
\hline Total & 100 & 100 \\
\hline
\end{tabular}

The atomic percentage of present element oxygen, calcium, and cadmium was found to be $86.50 \% 12.59 \%$ and $0.91 \%$ are present (14).

\section{UV-Visible Analysis:-}

Optical absorption spectrum was recorded on a UV-2400 PC Series UV-Visible spectrophotometer with performing wavelength ranging from 200nm to $900 \mathrm{~nm}$ as shown in Fig. 7(a) and 7(b). It is inferred from the spectra, that the grown pure calcium oxalate monohydrate and doped calcium oxalate monohydrate crystals have low absorbance in the entire UV-Visible region considered and the cut off wavelengths are around $249 \mathrm{~nm}$ and $247 \mathrm{~nm}$, closer to UV range from $247-900 \mathrm{~nm}$. The presence of lower cut off wavelength and the wide optical transmission window range are the most desirous properties of materials possessing NLO activity (15).

Fig 7:- ( a) UV-Visible analysis of pure calcium oxalate monohydrate crystal.

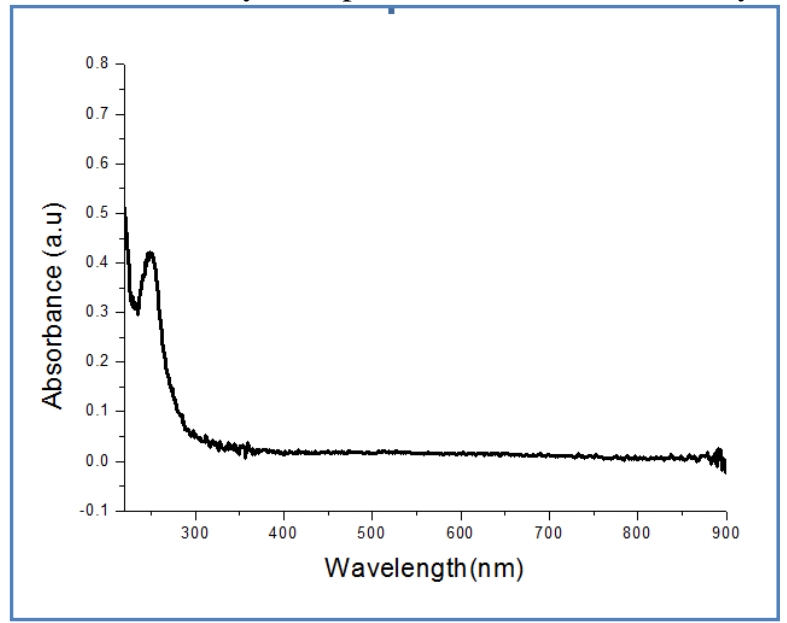

Fig. 7:- (b). UV-Visible analysis of cadmium doped calcium oxalate monohydrate crystal.

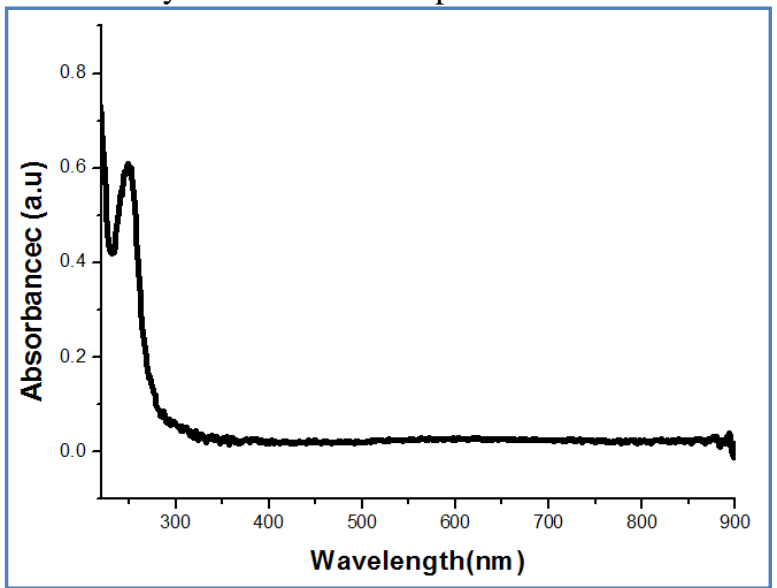

\section{Conclusion:-}

Gel growth technique is used to grown urinary type of crystals. FTIR spectrum was recorded and the functional group frequencies of pure calcium oxalate monohydrate and doped calcium oxalate monohydrate and cadmium doped calcium oxalate monohydrate crystal were analyzed. The functional groups are identified by FT-Raman 
spectra of pure calcium oxalate monohydrate and cadmium doped calcium oxalate monohydrate crystals. Powder XRD data confirms the crystal structure of the pure calcium oxalate and cadmium doped calcium oxalate monohydrate crystals. SEM images shows the crystals are grown by monoclinic, prismatic, and hexagonal prismatic and plate like shape. The incorporation of cadmium in the crystals of calcium oxalate monohydrate has been confirmed by energy dispersive X-ray analysis. The optical properties were determined by UV-Visible analysis.

\section{References:-}

1. Vladimir Uvarov, Inna Popov, Nandhakishore shapur et al., 'X-ray diffraction and SEM study of kidney stones in Israel'. Quantitative analysis crystallite size determine and statistical characterization, Environ. Geo.chem. Health, 2011, (33), 613-622.

2. Mohamed Ali, N. Arunainambi Raj, S. Kalainathan, \& P. Palnichamy, 'Micro hardness and acoustic behavior of Calcium Oxalate urinary stone'. Material Letters, 2008, (62), 2351-2354.

3. Moroz, T.N. Palchik, N.A. Dar, A.V, 'Micro elemental and mineral compositions of pathogenic bio mineral concernments: SRXFA, X-ray powder diffraction and vibration spectroscopy data'. Nuclear instruments and methods in physics Research section A: Accelerators, Spectrometers, Detectors and associated equipment, 2009, (603), 141-143.

4. Singh R, P Gawr SS White DJ and Nancollas GH, Surface effects in the crystal growth of calcium oxalate monohydrate'. Collid and interface science, 1987,118, 379-386.

5. Suresh, P. Kanchana, G. Sundaramoorthi, 'Growth and characterization studies of MnHP single crystal in silica gel Medium'. Journal of Minerals Materials Characterization Engineering, 2009, (8), 349-357.

6. Achillesa W, Feritag R, Kiss B,Ridemiller, 'Qualification of crystal growth of calcium oxalate in gel and its modification by urinary constituents in a new flow model of crystallization'. J Urol. 1995, (154), 1552-1156.

7. Kalkura SN, Vaidyan VK, Kanakavel M, Ramasamy P. 'Crystallization of Uric acid'. J. Cryst Growth.1993, (132), 617-620.

8. G. Madhurambal, N. Prabha, S.P. Lakshmi S. C. Mojumdar, 'Thermal, UV, FTIR and XRD studies of urinary stones'. J. Therm Anal Calorim .2013, (112), 1067-1075.

9. Eascolar E \& Ballanato 'Analysis of feline urinary calculi and urethral plugs by infrared spectroscopy and scanning electron microscopy’. J Vet. Rec. 2003, (152), 625-628.

10. R. Selvaraju and S. Sulochana, 'In-vitro Growth and Inhibition Studies of Tribulus Terrestris on Calcium Oxalate Monohydrate Crystals'.International Journal of science and Research, 2016, 5(6), 83-87.

11. D.Valarmathi, Leela Abhram, \& S. Gunasekaran, 'Growth and characterization of agar gel Brushite crystals'. Indian Journal of Pure and Applied Physics, 2010, (48), 36-38.

12. Selvaraju R, A Raja, G Thiruppathi, 'Chemical composition and binary mixture of human urinary stones using FT-Raman spectroscopy method', Spectrochimica Acta Part A: Molecular and Bio-Molecular spectroscopy. 2013, (114), 650-657.

13. V.B. Suryawanshi, R.T. Chaudhari, 'Growth and study of micro- crystalline Calcium Oxalate Monohydrate Crystals by agar gel system', Archi of Phy. Res, 2014, 5(2), 38-44.

14. V.B. Suryawanshi and R.T. Chaudhari, 'Effect of neutral gel on nucleation and growth of urinary calcium oxalate monohydrate crystals in agar gel'. Archieves of Physics Research.2015, (1), 7-12.

15. Mary Freeda, R. Krishna Priya, T.H. Freeda and S. Mary Delphine, Crystallization and characterization of mixed crystals of strontium calcium barium tartrate'. Archievees of Applied Science Research, 2012, 4(1), 128-136. 